\title{
CUIDADO DA VIDA E CUIDADO DE SI: SOBRE A INDIVIDUALIZAÇÃO BIOPOLÍTICA CONTEMPORÂNEA
}

\author{
Cesar Candiotto \\ Pontifícia Universidade Católica do Paraná/CNPq
}

\begin{abstract}
In the 1979 course, entitled Naissance de la biopolitique, Michel Foucault proposes contemporary neoliberalism, especially in its North American variant, as one of the most expressive biopolitical governmentality instance of our time. This article examines if the care of the life and its articulation with the constitution of the individual as a free entrepreneur of himself, observable in this biopolitics, can be considered as a contemporary unfolding of the "care of the self", the nuclear concept in Foucault's last writings. It suggests that the care of the self, understood as a principle of permanent concern whose scope is the transformation of the self and the creation of new ways of being and living, leads us away to point two conclusions: the first one is that the neoliberal care of the life is inseparable from the management of the individuals' freedom; the second one is that the neoliberal selfgovernment, considered by means of the calculation of economic self-investment, it is something from which one should get rid of.
\end{abstract}

KEYWORDS: governmentality, politics, care of the life, care of the self.

RESUMO: No curso de 1979, intitulado Naissance de la biopolitique, Michel Foucault propõe que o neoliberalismo contemporâneo, principalmente na sua variante norteamericana, seja lido como uma das mais expressivas configurações da governamentalidade biopolítica de nossa época. $O$ artigo analisa se o cuidado da vida e sua articulação com a constituição do indivíduo como livre empreendedor de si mesmo, observável nessa biopolítica, podem ser considerados desdobramentos contemporâneos do "cuidado de si", conceito nuclear nos últimos escritos de Foucault. Sugere-se que o cuidado de si, entendido como princípio de inquietude permanente cujo escopo é a transformação de si mesmo e a criação de novas maneiras de ser e de viver, permite apontar duas conclusões: a primeira delas, que 0 cuidado neoliberal da vida é inseparável da gestão da liberdade dos indivíduos; a segunda, que 0 autogoverno neoliberal, considerado pelo cálculo do investimento econômico em si mesmo, é algo do qual convém desprender-se.

PALAVRAS-CHAVE: governamentalidade, política, cuidado da vida, cuidado de si. 


\section{INTRODUÇÃO}

A problematização da biopolítica em 1976, no livro Histoire de la séxualité, I: la volonté de savoir e no curso Il faut deféndre la société, pareceu ter provocado na investigação de Foucault um deslocamento, da constituição do indivíduo moderno como homem-máquina no poder disciplinar para a constituição da população, definida não em termos geográficos pelo conjunto de seres humanos pertencentes a uma unidade territorial, mas sim em seu aspecto vital, como espécie vivente agrupada em torno de uma característica biológica peculiar: doença, ascendência genética, insanidade e assim por diante.

Essa perspectiva da biopolítica ${ }^{1}$ teve sua continuidade nas três primeiras aulas do curso Sécurité, territoire, population. A partir da quarta aula - dia $1^{\underline{a}}$. de fevereiro de 1978 - Foucault pareceu minimizar a biopolítica ao enfatizar a genealogia da governamentalidade, desde o pastorado cristão medieval do governo das almas até seus desdobramentos na época contemporânea, ao se referir ao modo como convém governar uma população.

Pelo viés da governamentalidade, a racionalidade política torna-se objeto da investigação foucaultiana pela primeira vez. Foucault aponta dois modus operandi herdados do poder pastoral religioso cristão, que continuam presentes, ainda que com objetivos diferentes e secularizados, na atuação das políticas liberais modernas e contemporâneas: a totalização e a individualização. A totalização corresponde aos processos de objetivação da população por mecanismos que regulam seus fluxos vitais; já a individualização, diz respeito aos processos de normalização e modelação presentes nas práticas políticas que impelem alguém a se reconhecer a partir de uma identidade que não foi criada por ele, mas uma espécie de autoimagem mimética da qual ele se torna dependente. ${ }^{2}$

\footnotetext{
${ }^{1} \mathrm{Na}$ verdade, não existe somente uma perspectiva da biopolítica em Foucault. Talvez fosse melhor situá-la no plural, como biopolíticas. Essa pluralidade é decorrente dos próprios deslocamentos da problemática do poder em sua investigação. Para um estudo sobre a trajetória da biopolítica em Foucault, remetemos a E. Castro. "Biopolíica: de la soberanía al gobierno". In: Rev. latinoam. filos., Ciudad Autónoma de Buenos Aires, v. 34, n. 2, nov. 2008.

2 No liberalismo, entendido como doutrina política, o indivíduo é um pressuposto, átomo social para 0 qual deve ser garantida uma jurisdição sobre suas preferências: “...o fundamento do liberalismo político se reconhece (...) ligado à promoção do individualismo, se por isso entendemos o valor último que um sistema político reconhece ao indivíduo e à sua singularidade expressa sob a forma de um grau de independência substancial que the é concedido por sua sociedade ou seu grupo de referência."
} 
A biopolítica moderna, resultado da aliança entre ciências humanas e soberania política estatal, afirma que cuida da vida do conjunto da população e ao mesmo tempo protege os indivíduos. Essa mútua imbricação entre totalização e individualização mostra que Foucault não abandonou a biopolítica e o poder disciplinar quando passa a discorrer sobre a governamentalidade. $\mathrm{Na}$ verdade, foi a partir dos procedimentos de totalização (regulação biopolítica) e individualização (normalização disciplinar) que racionalidades políticas, como o liberalismo moderno e as várias vertentes do neoliberalismo contemporâneo, puderam ser entendidas como técnicas de governamentalidade.

Em 1979, no curso Naissance de la biopolitique, Foucault se detém em uma modalidade específica de governamentalidade contemporânea, que é a neoliberal. ${ }^{3}$ Nesse curso é que podemos entender por que ele situa o neoliberalismo como o maior exemplo de governamentalidade biopolítica de nossa época.

Nossa investigação pode ser formulada nestes termos: se o neoliberalismo é uma modalidade de governamentalidade biopolítica centrada no cuidado da vida, seria esse cuidado um desdobramento

(LAZZERI, 2000, p. 200). Foucault entende que é uma ficção liberal situar o indivíduo como átomo social, como pressuposto filosófico. O que deixa de ser fictício são os processos de individualização, de constituição, fabricação e produção do indivíduo nas práticas sociais e políticas (FOUCAULT, 1975, p. 172). Depreende-se que, no recorte de Foucault, o indivíduo jamais é o ponto de partida da sociedade, mas sempre ponto de chegada dos processos de individualização. Em consequência, "a ideia que 0 indivíduo é um sujeito de ação, contínuo e idêntico a si mesmo, deve ser abandonada; deve-se também abandonar a ideia de que o indivíduo é uma premissa, um 'dado', de que os atores que se relacionam com ele e o observador científico que o estuda, deveriam tomá-lo como algo já adquirido." (PIZZORNO, 1988, p. 238). Em razão da pertinência da leitura foucaultiana da governamentalidade biopolítica liberal e neoliberal, priorizamos o termo "indivíduo" e a expressão "processos de individualização", ao mesmo tempo em que preterimos o termo e a expressão "sujeito" e "processos de subjetivação", respectivamente. Estes últimos somente serão preservados quando forem objetos de citação literal.

${ }^{3}$ Como se sabe, a rigor é inadequado e até pejorativo se referir ao liberalismo contemporâneo como (neo) liberalismo. Todavia, no curso de 1979, Naissance de la biopolitique, Foucault usa esse conceito sem qualquer advertência. Sua démarche ajuda ainda a rever, retrospectivamente, a interpretação compacta e reducionista do neoliberalismo como "pensamento único", como apontaremos no decorrer do artigo. Desde a perspectiva do seu modus operandi, inexiste um único neoliberalismo: há o ordoliberalismo alemão (principalmente em pensadores como Eucken, Röpke, Rüstow, Müller-Armack), 0 anarcoliberalismo americano (inspirado em pensadores da Escola Austríaca, tais como Mises e Hayek e membros da Escola de Chicago, como Milton Friedman, Gary Becker, Theodore Schultz), e 0 neoliberalismo francês, cuja importância no curso não é a mesma que a atribuída às modalidades anteriores. Neste artigo, iremos privilegiar a maneira como o assim chamado neoliberalismo norteamericano ou anarcoliberalismo propõe um singular investimento da vida e constituição do indivíduo. É dele, portanto, que nossas conclusões são deduzidas. 
contemporâneo do cuidado de si, que Foucault identificou mais tarde entre os antigos? Nesse sentido, nosso escopo é examinar se a constituição do indivíduo como livre empreendedor de si mesmo, tal como observável na governamentalidade biopolítica neoliberal, é uma modalidade de cuidado de si ou se, pelo contrário, essa determinação constitui uma insidiosa tentativa contemporânea de modelação do indivíduo e controle de seus fluxos vitais.

Nossa hipótese é mostrar que, se tomarmos não somente o curso de 1979, mas também o conjunto de ditos e escritos dos anos seguintes, seria possível avaliar criticamente o cuidado da vida e a constituição do indivíduo empreendedor a partir da perspectiva do cuidado de si.

Essa avaliação impõe priorizar atribuições específicas tanto ao cuidado da vida quanto ao cuidado de si. O cuidado da vida neoliberal é aquele voltado para a constituição do indivíduo somente a partir do investimento em si mesmo, pensado nos limites racionais do cálculo entre custos e benefícios econômicos. A noção de cuidado de si aqui, por sua vez, é aquela que encontramos em L'herméneutique du sujet, como "princípio de agitação e inquietude permanente" (FOUCAULT, 2001, p. 9) cujo télos é a transformação de si mesmo e a criação de novas maneiras de ser e de viver. Somente a partir dessa atribuição é que o cuidado de si pode auxiliar a apontar os limites e ambiguidades daquele cuidado da vida e seu processo de constituição do indivíduo.

Primeiro esboçamos a percepção do neoliberalismo como programa político e ideologia, da qual Foucault se afasta; em seguida mostramos que foi a introdução da governamentalidade que lhe permitiu ver o neoliberalismo como uma configuração biopolítica; nuançamos posteriormente que Foucault vê o neoliberalismo como uma maneira de pensar e de agir, de ser e de viver; consequentemente, um dos maiores projetos de investimento da vida e, por meio dela, de processos de individualização. Enfim, tentamos demonstrar que a investigação subsequente de Foucault, centrada no fio condutor do cuidado de si, pode ser uma chave analítica para a determinação dos limites do autogoverno neoliberal.

\section{Neoliberalismo como programa político e ideologia}

A análise de Foucault a respeito do neoliberalismo contemporâneo é ímpar porque ele não o entende no quadro de uma doutrina política no sentido de Estado mínimo, mas como racionalidade política governamental. 
A maioria dos críticos do neoliberalismo o situa como doutrina e programa político que se impôs nos países ocidentais a partir do final dos anos 1980 e provocou uma transformação na esfera ideológica.

Segundo Jason Read (2009, p. 26):

O neoliberalismo, nos textos que o têm confrontado criticamente, é geralmente entendido não somente como uma nova ideologia, mas uma transformação da ideologia, em suas condições e efeitos. Em termos de suas condições, é uma ideologia que é gerada não a partir do estado, da classe dominante, mas da experiência cotidiana de comprar e vender do mercado, que é então estendida através de outros espaços sociais, 'o mercado de ideias', para tornar-se uma imagem da sociedade. Em segundo lugar, é uma ideologia porque se refere não somente à esfera política, a um ideal de estado, mas à plenitude da existência humana. Ele exige apresentar não um ideal, mas uma realidade: a natureza humana.

Perry Anderson (1995, p. 22), conhecido teórico de esquerda, afirma o seguinte:

(...) o neoliberalismo é um movimento ideológico em escala verdadeiramente mundial, como o capitalismo jamais havia produzido no passado. Trata-se de um corpo de doutrina coerente, autoconsciente, militante, lucidamente decidido a transformar todo o mundo à sua imagem, em sua ambição estrutural e sua extensão internacional. Eis aí algo muito mais parecido ao movimento comunista de ontem do que o liberalismo eclético e distendido do século passado.

Nessa mesma linhagem teórica Ramonet (1997, p. 23), apresenta o neoliberalismo como um pensamento único hegemônico, pois "trata-se da tradução em termos ideológicos da pretensão universal dos interesses de um conjunto de forças econômicas, em particular do capital internacional”.

Estudos relativamente recentes apontam que, nos anos oitenta, o neoliberalismo conseguiu uma notável expansão, ao convencer até mesmo aqueles que sustentavam o desenvolvimento baseado no Estado, sejam capitalistas ou socialistas. Exemplo disso é a implementação de políticas neoliberais em governos socialdemocratas europeus na Espanha, França, 
Grécia, Itália e Portugal, assim como em correntes nacionalistas e populistas na América Latina, como no peronismo argentino e no Partido Revolucionário Institucional, do México. O neoliberalismo espraiou sua poderosa hegemonia em âmbito mundial tanto como liderança intelectual quanto como força política. Mas essa expansão, mais do que geográfica, diz respeito também à penetração em domínios que ideologias políticas anteriores jamais haviam alcançado.

Ainda segundo os críticos de linhagem marxista, esse ideário não se limita ao âmbito econômico, já que ele estende seus tentáculos ao modo de uma expansão integral no sentido de um novo projeto de sociedade imposto pela política exterior norte-americana.

Ao contrário dos desenvolvimentos teóricos que apresentam o fim das grandes narrativas e dos grandes relatos (tais como o partido, a nação, Deus) na segunda metade do século $\mathrm{XX}^{4}$, o neoliberalismo permanece como um macrorrelato único que reina soberanamente na época atual (Cf. HINKELAMMERT, 1996). Esse relato hipostasia o mercado como instância intocável, controlável por leis imutáveis e dadas como as que regem a natureza. Em síntese: "economicamente o neoliberalismo fracassou, pois não conseguiu nenhuma revitalização básica do capitalismo avançado. Socialmente, funcionou criando sociedades mais desiguais. Política e ideologicamente, teve grande sucesso, pois se impôs como única alternativa. Ou seja, constitui-se numa verdadeira força hegemônica." (ANDERSON, 1995, p. 23).

$\mathrm{Na}$ época que Foucault ministrou seu curso, Naissance de la biopolitique, provavelmente não poderia chegar a conclusões semelhantes. Uma das razões é que a implantação, expansão e consolidação do neoliberalismo como programa político nos países ocidentais e até mesmo do Leste europeu ocorrerá somente nas duas décadas seguintes. Foucault trata do neoliberalismo sem que ainda tenha outros parâmetros para avaliar seus resultados político-econômico-sociais, como procederam outros teóricos nos anos que se seguiram ao governo de Margareth Thatcher (1979), de Ronald Reagan (1980), Helmut Khol (1982) ou, no caso da América Latina, as

${ }^{4}$ Cf. Jean Franços Lyotard. A condição pós-moderna. 5a. ed. Rio de Janeiro: J. Olympio, 1998. 
experiências-piloto do Chile e da Bolívia e sua expansão como modelo político-econômico para os demais países desse Continente. ${ }^{5}$

A outra razão, mais fundamental, é que para Foucault ainda hoje seria insuficiente analisar o neoliberalismo somente em termos de seu sucesso ou fracasso como programa político e ideologia, como faz Perry Anderson.

Foucault se afasta da perspectiva que situa de um lado a prática e de outro a teoria, a infraestrutura e a superestrutura, o poder unicamente como exploração econômica e sua justificação ideológica ao nível das crenças, das maneiras de pensar. Não haveria unicamente uma ideologia política legitimadora daquilo que ocorre nas práticas de produção do capital e exclusivamente nessas práticas. ${ }^{6}$

O problema da noção de ideologia é que tacitamente tem sido apresentada em "oposição virtual a alguma coisa que seria a verdade".

\footnotetext{
${ }^{5} \mathrm{~A}$ expansão do neoliberalismo para a América Latina foi possibilitada pela crise do pagamento das dívidas externas (que eclodiu no México em 1982). Com isso, funda-se um clube de credores externos, que passam a impor ajustes estruturais que impelem, por sua vez, o programa neoliberal. Entretanto, 0 neoliberalismo surge na América Latina através de duas experiências isoladas: Chile e Bolívia. A ditadura de Pinochet no Chile foi a primeira experiência neoliberal sistemática do mundo. 0 neoliberalismo chileno teve como pressuposto a abolição da democracia. O objetivo fundamental foi a quebra do movimento operário, considerando que a democracia em si mesma jamais havia sido um valor central do neoliberalismo. Em contraposição, a Bolívia, a partir de 1985 sob o governo de Sachs, foi a experiência-piloto que serviu de exemplo para o neoliberalismo do Oriente pós-soviético, aplicado principalmente na Polônia e na Rússia. Ao contrário do Chile, porém, o objetivo na Bolívia consistia na contenção da hiperinflação. Não houve nenhuma ditadura. Sachs era herdeiro do governo populista e nesse sentido pode-se afirmar que "a América Latina também iniciou a variante neoliberal 'progressista', mais tarde difundida no sul da Europa, nos anos de euro-socialismo". (ANDERSON, 1995, p. 20). No entanto, os casos de Chile e Bolívia foram experiências isoladas até o final dos anos 80 na América Latina. Na verdade, a virada neoliberal continental começou no México (Salinas, 1988), estendeu-se à Argentina (Menem, 1989), à Venezuela (Carlos Andrés Perez, 1989), ao Brasil (Collor de Melo, 1990) e ao Peru (Fujimori, 1990). Tais governos caracterizaram-se pelo êxito em curto prazo, pela abertura do mercado de capitais e o fim da economia de substituição de importações, mas também pelo autoritarismo político e pelo crescimento da desigualdade social. Para uma análise crítica do neoliberalismo na América Latina, ver: José Comblin. Le néolibéralisme. Pensée unique. Paris: L'Harmattan, 2003.

${ }^{6}$ Lazzarato afirma que, enquanto Marx analisava somente as práticas econômicas, Foucault leva em consideração uma multiplicidade de práticas. "A teoria marxiana concentra-se exclusivamente na exploração. As outras relações de poder (entre homens/mulheres, médicos/pacientes, professores/alunos) e as outras modalidades de exercício do poder (dominação, sujeição, submissão) são negligenciadas em função da dimensão ontológica da categoria trabalho (LAZZARATO, 2006, p. 62). Mais adiante, ele sublinha que o marxismo "reduziu as formas de subjetivação à classe; submeteu a criação de possíveis ao trabalho produtivo; 'achatou' as relações de poder e as transformou em exploração. A dialética marxista acelerou o processo de nivelamento, ao remeter toda a sociedade à relação capital/trabalho, a multiplicidade aos dualismos, a assimetria à simetria, arrastando tudo para 0 Estado, fazendo assim dele a cama do capitalismo." (LAZZARATO, 2006, p. 191).
} 
(FOUCAULT, 2000, p.7) 7 . Ao renunciar permanecer na partilha entre verdade e ideologia, Foucault volve seu olhar para a história e aponta como são produzidos efeitos de verdade em discursos, em si mesmos, nem verdadeiros nem falsos. Não é incumbência fundamental do pensamento a crítica dos conteúdos ideológicos vinculados aos discursos. "O problema não é mudar a 'consciência' das pessoas, ou o que elas têm na cabeça, mas o regime político, econômico, institucional de produção da verdade”. (FOUCAULT, 2000, p.14). Agrega ainda:

Cada sociedade tem seu regime de verdade, sua 'política geral' de verdade: isto é, os tipos de discurso que ela acolhe e faz funcionar como verdadeiros; os mecanismos e as instâncias que permitem distinguir os enunciados verdadeiros dos falsos, a maneira como se sanciona uns e outros; as técnicas e os procedimentos que são valorizados para a obtenção da verdade; o estatuto daqueles que têm o encargo de dizer o que funciona como verdadeiro. (FOUCAULT, 2000, p.12)

O afastamento de Foucault da análise do neoliberalismo como uma transformação da ideologia liberal ou de um programa de governo caracterizado somente nos termos do estado mínimo é consequência do modo como ele há tempo situava as relações de poder: elas não são projeções superestruturais da infraestrutura das relações de produção; tampouco emanam de uma teoria doutrinária do Estado. Foucault pensa as relações de poder desde outra perspectiva, razão pela qual também o neoliberalismo é estudado de outro modo.

\section{A governamentalidade biopolítica neoliberal}

Foucault situou o neoliberalismo como exemplo emblemático de biopolítica contemporânea. Gordon lembra que Foucault não faz juízos de valor sobre a doutrina neoliberal ou seu exercício efetivo de governo. ${ }^{8} \mathrm{~A}$

\footnotetext{
7 "Um dos objetivos de Foucault em seus estudos sobre as sociedades disciplinares é romper com 0 economicismo e a cultura dialética dos dualismos, e demonstrar a pobreza e o reducionismo das explicações da dominação pela ideologia" (LAZZARATO, 2006, p. 64).

8 "Um dos atributos conspícuos das leituras da governamentalidade de Foucault é sua serena e (num sentido weberiano) exemplar abstenção de juízos de valores. Em um substancial preâmbulo ele rejeita 0 uso do discurso acadêmico como um veículo de injunção prática ("gosto disso; odeio aquilo; faça isso;
} 
principal razão dessa ausência de juízos, favoráveis ou não, se deve justamente ao fato de tê-lo problematizado como racionalidade governamental. Enquanto tal, deixa de ser relevante discorrer sobre a prática governamental efetiva ou como os governantes governam; também se torna secundária a abordagem das doutrinas que fundamentam uma administração do Estado. Saber por que se governa ou qual o melhor regime de governo não the interessa e, sim, como governar e qual a melhor maneira de governar. ${ }^{9}$ A governamentalidade é o âmbito reflexivo das práticas de governo, a racionalização da prática governamental no exercício da soberania política.

Uma das raízes da problematização do poder pela governamentalidade é a releitura do isomoformismo aristotélico entre condução política, condução pedagógica e condução de si mesmo. Aristóteles, conforme Foucault, entendia o governo político não como a única maneira de governar, mas somente como um modo de governar entre outros.

Essa releitura permitiu que Foucault se afastasse da doutrina liberal segundo a qual há uma diferença qualitativa entre a esfera da administração pública do Estado e a esfera das relações sociais privadas. A doutrina liberal está assentada nessa divisão para postular que a sociedade civil é o limite da ação do Estado; o direito, o limite da soberania despótica.

Já o modus operandi do neoliberalismo tem estimulado a fluidez entre estas diferentes esferas do governo. Exemplo disso é a progressiva transferência das responsabilidades estatais, como o cuidado da saúde e os investimentos em educação para o âmbito das escolhas e responsabilidades individuais. Essa fluidez de competências, frequentemente vista como o fim

recuse aquilo..."), e rejeita a ideia de que as escolhas políticas práticas podem ser determinadas no interior do espaço de um texto teórico, como que trivializando o ato da decisão moral ao nível de uma mera preferência estética." (GORDON, 1991, p.6). Isso não exclui a simpatia pelos teóricos liberais e neoliberais que propõem uma arte de governar inventiva, ao contrário da cultura crítica de esquerda e do socialismo, que não possuem e jamais possuíram sua própria arte de governar específica porque ficaram limitados à problemática do Estado. "Em todo o caso, saibamos apenas que, se há uma governamentalidade efetivamente socialista, ela não está oculta no interior do socialismo e dos seus textos. Não se pode deduzi-la deles. É preciso inventá-la." (FOUCAULT, 2004b, p. 95).

9 "A questão colocada (...) não é, portanto, prioritariamente: por que governar? (que ressoaria como um 'a que bem governar?') -, a menos que se considere o anarquismo como a verdade do liberalismo, enquanto que ele é somente uma consequência que, contudo, transitou por outras correntes (Foucault mesmo pôde ser considerado por alguns como um pensador anarquista, o que está longe de ser manifesto) - mas bem, antes: como governar? Dito de outro modo, como fazer a distinção entre um artifício perturbador e um artifício facilitador?" (DELEULE, 2000, p. 104-105. Grifos do autor). 
da política ou o imperialismo da lógica do mercado, é somente efeito ou reestruturação das técnicas de governamentalidade, na percepção de Foucault.

Quando é adotada a perspectiva da governamentalidade, é possível desenvolver uma forma dinâmica de análise que não está limitada a enunciar a "ocaso da política" ou o "predomínio do mercado", senão que decodifica o tão famoso "fim da política" como um programa político. A crise do keynesianismo e o desmantelamento das formas de intervenção encarnadas no estado de Bem-estar não leva consigo tanto uma perda da capacidade do estado para governar, mas principalmente uma reestruturação das tecnologias de governo (LEMKE, 2006, p. 14).

Em razão disso é que Foucault vê também no neoliberalismo uma inovadora tecnologia do eu, um regime de saber-poder que atua na constituição do indivíduo. Além de ser uma tecnologia de governo política, o neoliberalismo está relacionado à constituição de uma nova maneira de pensar e de agir, de ser e de viver. Depreende-se que ele pode ser considerado um dos maiores projetos de investimento contemporâneo da vida.

\section{0 investimento da vida e a constituição do indivíduo}

No curso Naissance de la biopolitique, Foucault analisa o modelo da teoria do capital humano do neoliberalismo da Escola de Chicago, cujos expoentes mais conhecidos são G. Becker e T. Schultz. Esses autores propiciam a reinterpretação de dois elementos fundamentais da teoria econômica clássica, a saber: o capital e o trabalho. Essa reinterpretação indica que a constituição do indivíduo no liberalismo clássico não é a mesma que se observa no neoliberalismo contemporâneo.

Em Les mots et les choses (1966), Foucault afirma que na Idade Clássica (meados do século XVII até o final do século XVIII) a ênfase eram as trocas de riquezas e não as relações de trabalho. Era a época da análise das riquezas, quando ainda inexistia a economia política moderna. Ressalta que os clássicos só se preocupavam com a produção de bens oriunda do fator terra e do fator capital, mas praticamente esqueciam ou desqualificavam o fator trabalho. Caso emblemático de A. Smith, para o qual o trabalho é fator de produção passivo e não fator fundamental da economia. Somente na 
Modernidade (a partir do último quarto do século XVIII) o trabalho é considerado o principal fator de produção.

Provavelmente, aquele que melhor fez uma análise moderna do trabalho tenha sido Marx. Ele entende que o modo de produção capitalista depende fundamentalmente do fator trabalho. Por ele o homem transforma a realidade e transforma a si próprio. Significa que individuar-se como trabalhador é um dos efeitos revolucionários da modernidade, porque sem essa individuação não se pode transformar a realidade da exploração nas relações de produção e tampouco é possível transformar a si mesmo, de indivíduo alienado para um indivíduo desalienado. ${ }^{10}$

Em Naissance de la biopolitique Foucault lembra que os neoliberais da Escola de Chicago não dialogam com Marx; mas, caso este diálogo houve sido realizado, provavelmente o teriam acusado de não haver examinado o trabalho na sua realidade concreta. Com efeito, a extração da "força" e "tempo" do trabalho, que gera valor e da qual uma parte é extorquida, é considerada por Marx um efeito do modo capitalista de produção.

Marx apresenta a divisão entre trabalho abstrato e trabalho concreto como algo estrutural do capitalismo. Não obstante, no entender de G. Becker, essa divisão é tributária exclusivamente do modo como o trabalho é "representado" pela teoria econômica quando esta não leva em conta a lógica do capital e sua realidade histórica. Jamais, portanto, a divisão entre trabalho abstrato e trabalho concreto seria uma consequência do próprio capitalismo. Transformado em força de trabalho, medido pelo tempo, colocado no mercado e retribuído como salário, o trabalho é amputado de sua realidade humana e suas variáveis qualitativas.

\footnotetext{
${ }^{10}$ Marx entendia que o poder era dotado de fundações estruturais, no sentido de que ele não emana de uma vontade individual, mas da lógica das relações de produção ou das necessidades funcionais das organizações de um modo geral. Mas, como ressalta Pizzorno, "a 'vítima' do poder (...) era o indivíduo enquanto tal que aquele poder estrutural impede de se desenvolver como ele teria podido fazê-lo em outras condições." Marx, portanto, tem necessidade da pressuposição da imagem de um indivíduo portador de interesses verdadeiros, claramente identificáveis, válidos, duradouros. "Se a noção de "consciência falsa" pode ser utilizada a fim de explicar a conduta verdadeira do trabalhador no sistema capitalista, é porque existe uma 'consciência verdadeira', um interesse verdadeiro que, pode-se supor, constitui a identidade real do indivíduo sujeitado pelo poder." (PIZZORNO, 1988, p. 238). Essa é a razão pela qual podemos entender 0 processo de desalienação pelo termo individuação, e não individualização. A individuação é aqui entendida como a constituição de si mesmo como consciência verdadeira. Foucault, por sua vez, jamais trabalha com essa perspectiva da pressuposição de um indivíduo portador de interesses identificáveis e verdadeiros.
} 


\section{0 indivíduo empreendedor}

Pensadores, como G. Becker e T. Schultz, querem justamente situar o trabalho a partir de sua realidade concreta, a saber: o próprio trabalhador e suas escolhas racionais. Nesse sentido é que a teoria do capital humano (construída entre os anos 1960 e 1970) quer ser uma análise concreta do trabalho ao entendê-lo como conduta econômica racionalizada calculada por aquele que trabalha. A concretude do trabalho é mensurada pelo investimento que o trabalhador faz livremente em si mesmo, na condição de ser humano capitalizável.

Cito T. Schultz:

A característica distintiva do capital humano é a de que é ele parte do homem. É humano porquanto se acha configurado no homem, e é capital porque é uma fonte de satisfações futuras, ou de futuros rendimentos, ou ambas a coisas. Onde os homens sejam pessoas livres, o capital humano não é um ativo negociável, no sentido de que possa ser vendido. Pode, sem dúvida, ser adquirido, não como elemento de ativo, que se adquire no mercado, mas por intermédio de um investimento no próprio indivíduo. (SCHULTZ, 1973, p. 53, grifos do autor).

Se nenhuma pessoa pode separar-se do capital humano que possui significa que sua acumulação e preservação têm a ver com a constituição do próprio indivíduo. A acumulação desse capital humano envolve domínios exteriores e mais amplos que a clássica gestão do tempo de trabalho, pela qual era levado em consideração somente o trabalho exercido na fábrica.

A concretude da realidade do trabalhador e suas escolhas supõem um investimento extensivo à vida em todos os seus momentos e dimensões. Trata-se de administrar o uso adequado da existência completa do indivíduo: os afetos, o cuidado desde a gestação, a educação fora do sistema formal, a saúde, seus deslocamentos, seu tempo livre. ${ }^{11}$

11 Esse investimento é constituído: 1) pelo tempo que os pais dedicam aos filhos fora das atividades educacionais propriamente tais; a criança será muito mais adaptável dependendo do tempo de nutrição, de afeição, dos cuidados dados, do nível de cultura dos pais e dos estímulos recebidos; de onde uma análise circunstancial da vida da criança que poderá ser medida em termos de possibilidades de 
O cuidado da vida como capital permanente a ser aperfeiçoado e gerido será doravante a razão principal das escolhas racionais do trabalhador. Importante é que o trabalhador deixe se se individualizar como objeto de oferta e procura em razão de sua força de trabalho. Necessário é se constituir como um indivíduo ativo, como alguém que é "seu próprio capital", "seu próprio produtor" e a fonte de "seus próprios lucros", além de ser o autor de "sua própria satisfação”. (FOUCAULT, 2004b, p. 232. Grifos nossos).

A principal contribuição do neoliberalismo da Escola de Chicago é ter ampliado os conceitos de capital e de empresa para além do domínio econômico. Se capitalizar é o objetivo econômico maior de uma empresa, investir em capital humano é o escopo permanente do ser humano empreendedor. A vida do indivíduo em todas as suas dimensões é pensada da perspectiva de uma empresa múltipla, como, por exemplo, em sua relação com a família, com a propriedade e com a segurança. (FOUCAULT, 2004b, p. 247; ver p. 267, nota 2).

Um dos efeitos da generalização da forma-empresa do domínio econômico para outros domínios, como o da constituição do indivíduo, é a progressiva dissolução da oposição clássica entre trabalhador e empreendedor.

Evidentemente que essa generalização pode ser atribuível aos deslocamentos no modo de produção e distribuição da riqueza no capitalismo (do modelo fordista para o taylorista, por exemplo); mas ela também se deve à invenção de técnicas políticas, sociais e educacionais de modificação do "meio" em que se vive com o objetivo de modular as escolhas individuais na sua tentativa de adaptação permanente a esse meio modificável. ${ }^{12}$

investimento em capital humano (Cf. FOUCAULT, 2004b, p. 236); 2) pelos cuidados médicos, a partir dos quais o capital humano pode ser aperfeiçoado e utilizado no maior tempo possível; de onde as políticas de proteção à saúde bem como a higiene pública; 3) pela capacidade de um indivíduo de se deslocar, de sua mobilidade inclusive migratória. Ainda que a mobilidade represente um custo econômico e psicológico que demandam adaptação, seu objetivo maior é o investimento em melhorias salariais, status social e assim por diante. "O migrante é um investidor, é um empreendedor de si mesmo que faz um número de despesas e de investimentos para obter uma determinada melhoria." (Cf. FOUCAULT, 2004b, p. 236); 4) pelo investimento em inovação, em novas tecnologias; novas formas de produtividade resultam dos investimentos que foram feitos ao nível do próprio ser humano (cf. FOUCAULT, 2004b, p. 238).

12 O neoliberalismo investe na vida a partir de intervenções diretas na modificação do meio em que se vive e de técnicas indiretas de gestão da liberdade dos indivíduos, na medida em que a modificação do meio os leva a modificar seu comportamento e suas escolhas. Se o meio, cujas variáveis são artificialmente modificadas pela biopolítica neoliberal, é o mercado e sua lógica, então os indivíduos 
Modificado o meio, produzido como fluxo de capitais e regulado a partir do critério do cálculo racional de custos e benefícios, o trabalhador se vê como empreendedor, e sua força de trabalho, como capital a ser gerido por ele mesmo. Assim é que nas técnicas de governamentalidade neoliberais o indivíduo, porque se modula como empreendedor, precisa constituir-se em alguém responsável por suas escolhas e decisões.

Os efeitos em termos de individualização são notáveis: busca-se produzir um indivíduo responsável cuja qualidade moral esteja fundada na escolha racional de uma determinada ação em razão da relação entre custos e benefícios, ao mesmo tempo em que ações alternativas são relegadas a plano secundário. Cada indivíduo é levado a considerar-se um "igualmente desigual". ${ }^{13}$ "Exploração, dominação e toda outra forma de desigualdade social são tornadas invisíveis como fenômeno social ao ponto que cada condição social individual é avaliada somente como efeito de suas próprias escolhas e investimentos" (HAMANN, 2009, p. 43).

$\mathrm{Na}$ governamentalidade neoliberal o indivíduo é constituído não prioritariamente como átomo jurídico que obedece a regras em vista da persecução do bem coletivo, mas como ser calculista e racional cuja responsabilidade maior é velar pelo cuidado de sua vida, a saber: o correto investimento em seu capital humano. A vida não administrada é considerada como fracasso moral do indivíduo; quando isso ocorre ele é objetivado como alguém irresponsável por suas escolhas.

\section{0 indivíduo competitivo e adaptável}

Ao ser constituído como um empreendedor e único responsável por suas decisões e escolhas, também está em jogo na individualização neoliberal a lógica da competitividade.

constituídos em razão da adaptação a essas modificações são aqueles que passam a ver-se e a perceber-se como livres empreendedores de si mesmos, portadores de um capital humano a ser mantido e potencializado, diferentemente das demais formas de capital.

${ }^{13} \mathrm{O}$ que é único no neoliberalismo é que ele estabelece um continuum entre aqueles que estão confinados e os que não estão. "Ao passo que o Hospital Geral descrito por Foucault servia para constituir uma divisão entre os sujeitos normais e patológicos, a governamentalidade neoliberal aponta na direção da produção de algo como um plano social graduado ao constituir todo sujeito como 'igualmente desigual'. Encarcerado ou não, todos os sujeitos neoliberais são presumidamente 'iguais' e 'livres'." (HAMANN, 2009, p. 50). As divisões sociais existem, mas elas são atribuídas como fracassos resultantes de escolhas e responsabilidades do indivíduo. 
Se no liberalismo clássico a troca era considerada o elemento natural das relações exclusivamente econômicas ${ }^{14}$, no neoliberalismo a concorrência se torna o elemento fundamental não somente da economia, mas também das relações sociais e políticas (FOUCAULT, 2004b, p. 122). Entretanto, a concorrência não é vista como elemento natural da sociedade; ela é situada como "princípio formal"15 a ser protegido pelo Estado diante da natural tendência monopolista do mercado e da propensão intervencionista do próprio Estado. ${ }^{16}$

Nessa lógica da concorrência, alguém é empreendedor de si mesmo quando se subjetivar como indivíduo competitivo. A competição deve ser promovida, incentivada, estimulada, proporcionando desdobramentos reflexivos importantes no modo pelo qual ele é constituído.

\footnotetext{
${ }_{14} \mathrm{Na}$ idade clássica, sobretudo para Adam Smith, o homo oeconomicus, como homem da troca, era considerado um elemento intangível em relação ao exercício do poder político. A economia era pensada como limite da prática política. De onde a afirmação de que "O rei reina, mas não governa". Quer dizer, na medida em que a dinâmica das relações econômicas é aquilo que escapa à arbitrariedade da soberania política, o homem da troca é aquele que desafia o próprio poder político.

15 Os liberais clássicos do século XVIII deduziam a economia de mercado a partir da centralidade da troca, como princípio natural do laisser-faire. Os liberais do século XIX, por sua vez, enfatizaram a concorrência na economia de mercado, principalmente porque ela era considerada também um princípio natural do laisser-faire. Os ordoliberais alemães - na verdade, a versão alemã do neoliberalismo do pósguerra -, avaliaram essa percepção da concorrência como uma "ingenuidade naturalista". Para eles, 0 laisser-faire não pode ser deduzido do princípio da concorrência como forma organizadora do mercado. Os efeitos benéficos da concorrência não se devem a uma anterioridade natural, a um dado natural que traria consigo. "A concorrência tem uma lógica interna, ela tem sua estrutura própria. Seus efeitos somente serão produzidos se esta lógica for respeitada. De algum modo, trata-se de um jogo formal entre desigualdades. Jamais se trata de um jogo natural entre indivíduos e comportamentos" (FOUCAULT, 2004b, p. 124). Ora, inexiste concorrência pura; ela é um objetivo histórico de uma arte de governo, jamais um princípio natural a ser respeitado. A atuação do Estado não se limita mais em garantir e em fiscalizar para que uma suposta concorrência pura seja garantida; a atividade governamental estará inteiramente envolvida com a economia de mercado. A regra que definirá as ações governamentais terá como índice geral a economia de mercado. Conclui Foucault: "É necessário governar para o mercado, antes que governar por causa do mercado". (FOUCAULT, 2004b, p. 125). 0 Estado deverá intervir na economia somente em razão dos efeitos antissociais que a ausência de concorrência poderia produzir, como é o caso dos monopólios.

${ }^{16} \mathrm{Em} \mathrm{A}$. Smith encontramos a tese de que o Estado deve se limitar a instaurar e conservar as condições gerais que permitem aos mecanismos concorrenciais produzir seus efeitos. (SMITH, 1991, p. 430). Ela se tornou quase um credo no Traité d'économie politique, de J.-B. Say e foi radicalizada na Escola Austríaca, principalmente por $\mathrm{F}$. von Hayek. Essa radicalização admite que não somente as atividades mercadológicas devem ser protegidas de toda intervenção nefasta do poder político, "mas (também) 0 próprio mercado pode ser elevado ao patamar de um princípio político porque, na medida em que ele é instituído de modo a escapar a todo controle humano, encarna um princípio impessoal de alocação do maior número de recursos (riquezas, poderes, consideração), privando assim o poder político de toda intervenção arbitrária nesses domínios" (LAZZERI, 2000, p. 203).
} 
Para ser alguém competitivo deverá sentir-se produtivo, flexível e inovador em qualquer situação. A competitividade deixa de ser somente um mecanismo comum entre as empresas para estender-se de maneira avassaladora entre os próprios seres humanos e todas as relações sociais.

Ser objetivado como indivíduo competitivo demanda, paradoxalmente, que ele seja adaptável e manipulável às modificações nas variáveis do meio. Como pondera Becker, o indivíduo se subjetiva como homo oeconomicus quando ele "aceita (livremente) essa realidade". ${ }^{17}$ Sua conduta somente é considerada racional quando sensível a essas modificações nas variáveis na lógica do mercado. ${ }^{18}$ Nessa lógica é necessário produzir um indivíduo cuja resposta seja sempre sistemática, jamais aleatória. A economia será a ciência encarregada também do comportamento humano, da produção de respostas sistemáticas às variáveis da sociedade de mercado concorrencial (FOUCAULT, 2004b, p. 273). Essa sistemática da governamentalidade neoliberal nos leva a refletir sobre a pertinência da constituição do indivíduo e a caracterização do autogoverno como exercício da liberdade.

\section{A Gestão da liberdade}

Foucault deixava entender em suas intervenções que inexiste uma liberdade natural do ser humano. $O$ indivíduo livre não poderia ser identificado ao portador de interesses, que persegue certos fins. Ser livre não se limita a agir sem impedimentos externos, sem a coerção do poder público ou de outra natureza. ${ }^{19}$

17 "(...) aquele que é manipulável, e que responderá sistematicamente às modificações sistemáticas que serão introduzidas artificialmente no meio. (...) o homo oeconomicus aparece agora como o correlativo de uma governamentalidade, que vai agir sobre o meio e modificar sistematicamente as variáveis do meio". (FOUCAULT, 2004b, p. 274).

${ }^{18}$ No liberalismo clássico, o mercado era visto como uma realidade quase-natural, já existente, situada entre uma espécie de reserva econômica em um espaço supervisionado pelo Estado. No Ordoliberalismo a lógica do mercado não é vista como algo natural, mas como "constructo social desenvolvido que deve ser protegido e que, portanto, requer uma instituição positiva e um quadro jurídico para que o jogo da empresa funcione plenamente." (PETERS, M. A., 2001, p. 80). A Escola de Chicago, portanto, prolonga essa concepção do Ordoliberalismo alemão.

${ }^{19}$ Essa era a concepção juridicamente codificada de liberdade, atrelada ao individualismo, se por este último entendermos o valor último que um sistema político reconhece ao indivíduo e à sua singularidade sob a forma de um grau de independência substancial que the é concedida pela sociedade. Essa independência substancial protegida juridicamente é o que Hugo Grotius, no clássico Le droit de la guerre et de la paix (1625), denominará de "direito subjetivo", retomado por Hobbes como direitoliberdade e que mais tarde I. Berlim, depois dos estudos de J. Bentham e B. Constant, conceitua como liberdade negativa. Esta última, é entendida como "uma espécie de ato de 'cidadania mínima' que na 
Quando Foucault analisa o poder nos termos da governamentalidade, define esta como a arte da condução de condutas ou a tentativa de determinação das possibilidades de ação de outrem como princípio do próprio agir.

A liberdade é identificada como efeito de ações que podem tanto limitar o campo de possibilidade de outras ações, como também não se deixar determinar inteiramente por elas. Significa que os indivíduos são livres quando agem, diferentemente da concepção segundo a qual há ações livres quando emanadas de um indivíduo já livre. Depreende-se a afirmação foucaultiana de que não existe a liberdade, mas práticas de liberdade que podem criar e produzir modos de se governar, como também limitar e resistir ao governo de outrem. O exercício do governo é a arte de gerir e delimitar o campo de possibilidades do exercício da liberdade.

Analisado pelo viés da governamentalidade o neoliberalismo é muito mais do que uma doutrina econômica e muito menos do que uma doutrina política. Ele é considerado uma racionalidade refletida que atua na "organização" e "gestão" do campo possível a partir do qual podemos nos considerar seres livres. ${ }^{20}$

Por exemplo, o cuidado da vida e sua proteção são pensados não como atribuição do Estado, mas algo da esfera das decisões, escolhas e responsabilidades livremente exercidas pelos indivíduos. Sem deixar que eles se sintam livres para atuar, suas ações podem ser moduladas se forem modificadas as variáveis do campo de possibilidades no qual ele vive.

teoria consiste na defesa exclusiva dessa esfera de liberdade contra os impedimentos da potência pública quando ela obstaculiza a jurisdição do agente sobre suas preferências aí compreendidas, por consequência quando ela formula uma demanda de serviço cívico que consiste em constranger o agente a defender seus próprios direitos." (LAZZERI, 2000, p. 200).

${ }^{20}$ Preservadas suas diferenças, raciocínio semelhante pode ser feito em relação ao liberalismo clássico. Se como doutrina política ele é considerado a fonte das liberdades e garantias individuais e, como doutrina econômica, a origem da ideia de liberdade de mercado, já pelo viés da governamentalidade, 0 liberalismo é a arte de produzir e consumir liberdades. De um lado o liberalismo consome e necessita da liberdade na medida em que funciona somente a partir de um determinado número de liberdades: de mercado, de circulação, de expressão; mas, de outro, tal maneira de governar administra o campo da liberdade, quer dizer, a gestão e organização das condições a partir das quais se pode ser livre. 0 termo liberal se refere justamente a essa estreiteza da liberdade. "A nova arte governamental vai apresentar-se portanto como gestora da liberdade, não no sentido do imperativo : "seja livre", com a contradição imediata que esse imperativo pode trazer. (...) O liberalismo, no sentido em que eu 0 entendo, esse liberalismo que podemos caracterizar como a nova arte de governar formada no século XVIII, implica em seu âmago uma relação de produção/destruição em relação à liberdade. De um lado, é preciso produzir liberdade, mas esse mesmo gesto implica que, de outro, se estabeleçam limitações, controles, coerções, obrigações apoiadas em ameaças etc." (FOUCAULT, 2004b, p. 65). 
Nesse sentido é que Foucault afirma ser o neoliberalismo a "condição de inteligibilidade da biopolítica de nossa época” (FOUCAULT, 2004b, p. 24). Se nas disciplinas atuava-se diretamente na normalização do indivíduo pela otimização de seu corpo e o enfraquecimento de sua vontade, na biopolítica, desde a segunda metade do século XVIII, há uma atuação direta e constante na regulação do território e, indiretamente, na constituição de uma população. No caso da biopolítica neoliberal, opera-se também sobre a vida, porém de modo indireto. Não se trata somente de normalizar o indivíduo ou de regular seus processos vitais como parte de uma população, mas principalmente de modular condições, possibilidades e efeitos de suas ações pela intervenção e delimitação recorrente no seu campo de possibilidades.

Sem que o indivíduo moderno tenha deixado de ser fabricado pelas técnicas de poder disciplinares e seus mecanismos de normalização que atuam sobre o corpo; sem que a população tenha deixado de ser constituída pelo biopoder e as técnicas reguladoras da vida em seu sentido biológico, adentramo-nos na era das técnicas de governamentalidade neoliberais, que atuam sobre as motivações, desejos e aspirações que impelem as ações. Ao mesmo tempo em que as técnicas de governamentalidade neoliberais são menos restritivas e corporais ao não se preocuparem em confinar e fixar os corpos de maneira segmentada para o sistema produtivo; na medida em que elas não são essencialmente mecanismos de regulação e intervenção que atuam diretamente sobre a vida biológica, em compensação elas são intensas ao saturar o campo das ações livres possíveis.

Trata-se da administração do cálculo entre interesses, liberdades e riscos; e é justamente para minimizar os riscos que atuam os dispositivos de segurança. Um dos efeitos da articulação entre técnicas de governamentalidade e dispositivos de segurança é a constituição de indivíduos situados entre a livre competitividade e a insegurança social. Para garantir que alguém se individualize como livre e competitivo, é mister a produção de dispositivos e princípios de precaução ${ }^{21}$ que atenuem os perigos ameaçadores à segurança dos indivíduos.

A questão a ser posta é a seguinte: em que aspecto esse cuidado da qualidade de vidados indivíduos não seria o correlato de um controle intenso

${ }^{21}$ Sobre as dimensões filosóficas, jurídicas e políticas do princípio de precaução (cf. EWALD, F.; GOLLIER, Ch.; SADELEER, N. de., 2008). 
das possibilidades reais e virtuais de sua vida qualificada (Bios)? A politização intermitente do campo vital por parte da governamentalidade neoliberal e as ciências que a apoiam, não teriam tornado a qualidade de vida em uma vida sem qualificações?22 Este cuidado da vida pelo autogoverno neoliberal não desqualificou o cuidado de si, como princípio de inquietude e transformação de si mesmo?

\section{Considerações finais}

Em diversos momentos, entre o final dos anos 1970 e início do decênio de 1980, Foucault mostra uma série de lutas estratégicas que os indivíduos podem criar para que não sejam governados de uma determinada maneira por certos agentes, como a da população que resiste a uma medicação ou a criação de estilos de viver que se contrapõem a uma vida administrada. Essas lutas constituem posturas críticas a formas contemporâneas de governamentalidade, especialmente às técnicas administrativas que intervêm constantemente num meio a fim de, indiretamente, modular as escolhas e decisões individuais. Essas técnicas procuram atribuir uma identidade aos indivíduos pela constituição de um saber "verdadeiro" sobre eles; igualmente, elas buscam ofuscar as diferenças reais que fazem deles, seres irredutivelmente singulares.

Foucault tem insistido que a partir do século XIX, o acesso à verdade é oferecido quase que exclusivamente pelo conhecimento científico. Ciências do homem, como a psicologia, a psiquiatria; ciências sociais aplicadas, como a administração e a estatística; e ciências da vida, com a biologia e a biomedicina, procuram mediar, pelo cuidado da vida e a modulação do comportamento, o acesso à verdadeira identidade dos indivíduos. Essas mediações do cuidado da vida e da modulação das condutas exerceram um papel fundamental para as novas formas biopolíticas de governamentalidade, como a do neoliberalismo.

\footnotetext{
22 "As sociedades, transformadas em população (no dizer de Foucault na aula A governamentalidade: 'conjunto de seres vivos'), inscrevem novas linhas do político, fazendo da saúde, da fome, da segurança, da higiene, dos 'estilos de vida', uma instância de permanente luta, intervenção e politização (recentemente, por exemplo, foi a 'qualidade de vida', essa fórmula chave da era neoliberal, a que transformou os imaginários da 'vida digna' em oposição a uma vida sem qualificações, sem valor, sem qualidade)". (GIORGI, G.; RODRÍGUEZ, F., 2007, p.11).
} 
Penso, porém, que jamais elas podem ser incluídas no conjunto das práticas envolvidas pelo fio condutor do cuidado de si, como problematizado por Foucault nos anos 1980, principalmente em L'hermeneutique du sujet.

As técnicas de governamentalidade neoliberais que operam pela individualização/administração da vida ao modo de uma empresa múltipla, no sentido de levar o indivíduo a se reconhecer como responsável, competitivo, produtivo e empreendedor de si mesmo, encontram-se nas antípodas do cuidado de si como o senhorio e domínio de si para consigo.

Equívoca é a suposição de que Foucault teria visto na individualização neoliberal uma das possibilidades contemporâneas da constituição do indivíduo pelo cuidado de si. A modulação da vida de alguém como empresa para si mesmo não pode ser considerada uma "versão"23 do cuidado de si. No mínimo, trata-se da incitação a um tipo de cuidado da vida do qual é necessário permanentemente descuidar-se.

A compreensão do cuidado de si como "descaminho" para deixar de ser o que se é ou como "descuido" de uma vida constantemente pensada somente nos limites do empreendedorismo é fundamental em Foucault. $\mathrm{O}$ cuidado de si como "princípio de agitação, princípio de movimento, princípio de inquietude permanente" (FOUCAULT, 2001, p. 9) se afasta de qualquer apelo individualista ou identitário; antes, ele incita o desprendimento contínuo de nosso eu normalmente administrado e competitivo que atua somente a partir de escolhas já estabelecidas.

Cuidar de si é desprender-se do conhecimento de nós mesmos atrelado às identidades que a sociedade da administração e do empreendedorismo leva-nos a aceitar, a torná-las quase algo natural. As verdades associadas a tais identidades geralmente trazem embutidos efeitos de poder em função dos quais somos classificados e objetivados de responsáveis ou irresponsáveis, empreendedores ou fracassados, competitivos ou inadaptados.

Quando Foucault afirma que é preciso desprender-se do eu, ele se refere a esse eu mimético que individualizamos de maneira modulada. Paradoxalmente, o cuidado de si, como princípio de inquietude, implica num descuidar-se do eu livre, porém, administrado, da biopolítica neoliberal.

${ }^{23}$ Essa é a posição de Michel A. Peters, em seu livro Poststructuralism, Marxism, and Neoliberalism (2001, p. 81). 


\section{REFERÊNCIAS BIBLIOGRÁFICAS:}

ANDERSON, P. "Balanço do neoliberalismo". In: SADER, E.; GENTILI, P. (Orgs.). Pós-neoliberalismo: as políticas sociais e o Estado democrático. 3a . ed. São Paulo: Paz e Terra, 1995.

CASTRO, E. "Biopolítica: de la soberanía al gobierno". In: Rev. latinoam. filos., Ciudad Autónoma de Buenos Aires, v. 34, n. 2, nov. 2008 Disponível em: <http://www.scielo.org.ar/scielo.php?script=sci_arttext\&pid=S1852$73532008000200001 \& \operatorname{lng}=$ pt\&nrm=iso $>$. Acessos em 03 jun. 2011.

COMBlin, J. Le néolibéralisme. Pensée unique. Paris: L’Harmattan, 2003.

EWALD, F.; GOLLIER, Ch.; SADELEER, N. de. Le principe de precaution. Paris: P.U.F., 2008.

FOUCAULT, M. Surveiller et punir. Paris: Gallimard, 1975.

. Histoire de la sexualité, I: La volonté de savoir. Paris: Gallimard, 1976 (Coll. Tel).

Il faut défendre la société. Cours au Collège de France, 1975-

1976. Édition établie par François Ewald et Alessandro Fontana, par Mauro Bertani e Alessandro Fontana. Paris: Seuil/Gallimard, 1997. (Coll. Hautes études).

. Microfísica do Poder. 15a . ed. Organização e introdução de Roberto Machado. Rio de Janeiro: Graal, 2000.

. Sécurité, territoire, population. Cours au Collège de France,19771978. Édition établie par François Ewald et Alessandro Fontana, par Michel Senellart. Paris: Gallimard/ Seuil, 2004a. (Coll. Hautes études).

.Naissance de la biopolitique. Cours au Collège de France, 1978-1979. Édition établie par François Ewald et Alessandro Fontana, par Michel Senellart. Paris: Gallimard/Seuil, 2004b (Coll. Hautes études) 
. L’herméneutique du sujet. Cours au Collège de France, 1981-1982. Édition établie par Frédéric Gros. Paris: Gallimard/Seuil, 2001 (Coll. Hautes études).

GORDON, C. "Government rationality: An introduction”. In: BURCHELL, G.; GORDON, C.; MILlER, P. (eds.). The Foucault Effect: Studies in governmentality. Chicago, The University of Chicago Press, 1991, p. 1-51.

HAMANN, T. H. "Neoliberalism, Governmentality, and Ethics". In: Foucault Studies, n.6, pp. 37-59, February 2009.

HINKELAMMERT, F. El mapa del emperador: determinismo, caos, sujeto. San José de Costa Rica: DEI, 1996.

LAZZARATO, M. As Revoluções do capitalismo. Rio de Janeiro: Civilização Brasileira, 2006.

LAZZERI, CH. "Libéralisme”. In: Cités, n.2, Paris: PUF, 2000, p. 199-208.

LELEULE, D.; "L'héritage intellectual de Foucault": Entretien entre Didier Leleule et Francesco Paolo Adorno. In: Cités, n. 2, Paris: PUF, 2000, p. 99108.

LEMKE, T. "The Birth of Bio-Politics" - Michel Foucault's Lecture at the Collège de France on Neo-Liberal Governmentality. In: Economy and Society, v. 30, N. 2, pp. 190-207, May 2001.

LEMKE, T. 'Marx sin comillas'. Foucault, la Gubernamentalidad y la crítica del neoliberalismo. In: LEMKE, T.; LEGRAND, S.; LE BLANC, G.; MONTAG, W.; GIACOMELLI, M.E. Marx y Foucault. Buenos Aires, Nueva Visión, (Col. Claves), 2006. pp. 5-20.

LYOTARD, J. F. A condição pós-moderna. 5a. ed. Rio de Janeiro: J. Olympio, 1998.

PETERS, M.A. Poststructuralism, Marxism, and Neoliberalism: between Theory and Politics. Lanham, boulder; New York, Oxford: Rowman \& Littlefield Publishers, Inc.: 2001.

PIZZORNO, A. "Foucault et la conception libérale de l'individu". In: CANGUILHEM, G. (Ord.). Michel Foucault philosophe. Paris: Seuil, 1988. p. 236-244. 
RAMONET, I. “O pensamento único”. In: CARCANHOLO, M. D. (Org.). A quem pertence o amanhã? São Paulo: Loyola, 1997.

READ, J. "A Genealogy of Homo-Economicus: Neoliberalism and the Production of Subjectivity”. In: Foucault Studies, n.6, p. 25-36, February 2009.

RODRIGUEZ, F.; GIORGI, G. "Prólogo". In: Ensayos sobre biopolítica. Excesos de vida: Michel Foucault; Gilles Deleuze; Slavoj Zizek. Buenos Aires: Paidós, 2007, p. 9-34.

SMITH, A. La richesse des nations. Paris: Garnier-Flammarion, 1991.

SCHULTZ, T. O capital humano. Rio de Janeiro: Zahar, 1973.

Recebido em: junho de 2011 Aprovado em: setembro de 2011

Email: ccandiotto@gmail.com 